\title{
Preparation of monodisperse agglomerated pellicular anion-exchange resins compatible with HPLC solvents for ion chromatography
}

SINCE its introduction in 1975 by Small et al . ${ }^{[1]}$, ion chromatography has become the dominant analytical method for determining inorganic anions (and some organic anions) at ppm-ppb level. However, for a long time, the ion chromatography was usually used for the analysis of neat water samples such as tap water, rain and river. For the analysis of polluted water containing vairous organic compounds, rigorous pretreatment of the sample is necessary; otherwise, the chromatograph column would be contaminated by the organic compounds. Although these compounds can be cleaned up with HPLC solvents the column bed of polymer stationary phase could be damaged. An elute aqueous solution containing more than $10 \%$ methanol will cause substantial change of the column bed. This drawback restricted the column lifetimes and the development of applied field of the technique. Dionex company has successfully prepared columns for ion chromatography compatible with HPLC solvents through increasing cross-linked degree of the polymeric stationary phase since $1990^{[2]}$. With the new technique, treatment of the column using typicial eluent for reverse phase LC such as methanol or acetonitrile can remove the organic contaminants easily. However, the polymer beads used in the stationary phase were not monodispersive, and thus gave relatively high pressure of operation. Also to the best of our knowledge there has been no report regarding the preparation of this packing in detail. Here we would like to report the preparation and properties of polymeric stationary phase for ion chromatography using monodisperse and highly cross-linked $10-\mu \mathrm{m}$ polymer beads by seed polymerization.

Monodisperse polystyrene seed particles ( ca $1 \mu \mathrm{m}$ ) were prepared by emulsion polymerization of styrene in water in the absence of emulsifier under a nitrogen atmosphere using potassium persulfate as the initiator according to the method reported by Homola et al. ${ }^{[3]}$.

The monosized nonporous DVB particles were made by a two-step microsuspension process ${ }^{[4]}$, whereby radical bulk polymerizations took place in separate micrometre-sized droplets. In the first step, a low-molecular-weight, water-insoluble compound (such as $n$-hexadecane) was introduced into the above monosized $1-\mu \mathrm{m}$ polysyrene seed particles. In the second step the monomer mixture was absorbed in the activated seed particles and polymerized. Here $56.44 \%$ divinylbenzene was used as the monomer and highly cross-linked, monodisperse particles of $10 \mu \mathrm{m}$ were obtained. The range of particles is from 9.8 to $10.2 \mu \mathrm{m}$.

The ion-exchange latex used in this work was synthesized by copolymerization of $5 \%$ divinylbenzne with $95 \%$ vinylbenzyl chloride using emulsion polymerization techniques and then quaternized with dimethylethanolamine. The diameter of latex here was $0.1 \mu \mathrm{m}$.

The macroparticles of $10 \mu \mathrm{m}$ were surface-sulfonated with sulferic acid at $85^{\circ} \mathrm{C}$ for $15 \mathrm{~min}$. Then the surface-sulfonated particles and the above ion-exchange latex were mixed for $1 \mathrm{~h}$; the excess of emulsion was removed and the agglomerated pellicular stationary phase for ion chromatography was obtained. By controlling the emulsion particle size and the sulfonation degree of sulfonated particles, a $0.02 \mathrm{meq} / \mathrm{g} \mathrm{ex}$ change capacity of stationary phase was obtained. Pressure packing at $2.0 \times 10^{7} \mathrm{~Pa}$ using stainless steel columns employing Valco end fittings (Valco Instrument $\mathrm{Co}$. Inc.) was carried out with slurry method.

In the test of the columns a mixture of $2.8 \mathrm{mmol} / \mathrm{L} \mathrm{NaHCO}_{3}$ and $2.2 \mathrm{mmol} / \mathrm{L} \mathrm{Na}_{2} \mathrm{CO}_{3}$ was used as the eluent with a flow rate of $2 \mathrm{~mL} / \mathrm{min}$, and a $0.025 \mathrm{~mol} / \mathrm{L}$ sulferic acid solution was used as the regenerant with a flow rate of $138 \mathrm{~mL} / \mathrm{h}$, and the injection amount of $100 \mu \mathrm{L}$. The analytical columns previously prepared were evaluated by their ability to separate an injection of seven anions obtained from reagent grade salts in deionized water: $2.5 \times 10^{-6} \mathrm{~F}^{-}, 3.5 \times 10^{-6} \mathrm{Cl}^{-}, 8.0 \times 10^{-6} \mathrm{NO}_{2}^{-}, 20 \times 10^{-6}$ $\mathrm{PO}_{4}^{3}, 10 \times 10^{-6} \mathrm{Br}, 10 \times 10^{6} \mathrm{NO}_{3}$, and $20 \times 10^{-6} \mathrm{SO}_{4}^{2-}$. 
Table 1 Separation, retention times and column efficiency

\begin{tabular}{cccccccc}
\hline Anion & $\mathrm{F}$ & $\mathrm{Cl}^{-}$ & $\mathrm{NO}_{2}^{-}$ & $\mathrm{Br}^{-}$ & $\mathrm{NO}_{3}^{-}$ & $\mathrm{HPO}_{4}^{2-}$ & $\mathrm{SO}_{4}^{2-}$ \\
\hline $\begin{array}{c}\text { Concentration } \\
\left(\times 10^{6}\right)\end{array}$ & 2.5 & 3.5 & $\mathbf{8 . 0}$ & 10 & 10 & 20 & 20 \\
$\begin{array}{c}\text { Retention } \\
\text { times (min) } \\
\begin{array}{c}\text { Resolution } \\
\left(R_{3}\right)\end{array}\end{array}$ & 1.18 & 2.13 & 2.55 & 4.61 & 0.17 & 7.18 & 12.25 \\
$\begin{array}{c}\text { Efficiency } \\
\text { (plates/m) }\end{array}$ & 7084 & 18864 & 9955 & 13460 & 8760 & 13124 & 13572 \\
\hline
\end{tabular}

Seven anions were well separated from baseline on the column. The retention time, separation and column efficiency $\left(13500 / \mathrm{m}\right.$ for $\left.\mathrm{SO}_{4}^{2-}\right)$ can be seen from table 1 , and these are comparable with the product Dionex-AS4A-SC. Penetration and solvent compatible properties were tested with methanol as the eluent. After elution for $20 \mathrm{~min}$ the column pressure decreased from the starting $4.44 \times 10^{6} \mathrm{~Pa}$ to $3.57 \times 10^{6}$ $\mathrm{Pa}$, and the latter value was stable during further elution. After $3 \mathrm{~h}$ the column was eluted with the standard elution; the column pressure was recovered and stable at $4.44 \times 10^{6} \mathrm{~Pa}$. Retest of the separation of the anions gave the result exactly the same as before the elution with methanol indicating no damage of the column. It was noted that the low column pressure revealed a much better penetration in our case because of the monodispersability compared to the high pressure $\left(>8.23 \times 10^{6} \mathrm{~Pa}\right)$ of Dionex-AS4A-SC.

In summary we have successfully prepared HPLC solvent compatible, monodisperse stationary phase for ion chromatography.

Acknowledgement This work was supported by the National Natural Science Foundation of China (Grant No. 29635010)

\section{References}

1 Small, H., Stevens, T. S., Bauman, V. C., Novel ion exchange chromatographic method using conductimetric detection, Anal Chem., 1975, 17(12): 1801 .

2 John, R. S., Christopher, A. P., New latex-bonded pellicular anion exchangers with multiphase selectivity for high-performance chromatographic separations, J. Chromatogr., 1990, 499: 249.

3 Homola, A. M., Inoue, M., Robertson, A. A., Experiments with soap-free polymerization of styrene in the presence of alcohols, J. Appl. Polym. Sci., 1975, 19: 3077

4 Ugelstad, J., Mork, P. C., Swelling of oligomer-polymer particles. New methods of preparation of emulsions and polymer dispersions, Ad. Colloid Interface Sci., 1980, 13: 101.

\section{NING Jun', KONG Fanzuo', LI Dianhai ${ }^{2}$ and DU Yuezong ${ }^{2}$}

1. Research Center for Eco-Environmental Sciences, Chinese Academy of Sciences, Beijing 100085, Ching; 2. City Monitor Station of Waste Water Exclusion, Tianjin 300381, China

\section{Microwave radiation: a novel way to prepare new $\mathrm{Al}_{2} \mathrm{O}_{3}-\mathrm{NaY}$ shape- selective catalytic materials}

OWING to the existence of silicon component in zeolite framework, it is difficult to generate strong basicity on zeolite in the case of loading alkali metal salts ${ }^{[1]}$, although the strong basic zeolite catalysts are extremely desirable in industrial production because they often offer unique selectivity for several classes of reactions. Recently a novel way of preparing shape-selective solid strong bases has been reported by Zhu $\boldsymbol{e t}$ al. ${ }^{[2]}$, in which hydrolysis of aluminum isopropoxide was employed to coat a layer of alumina on the surface of zeolite $\mathrm{NaY}$. After the addition of basic compounds such as $\mathrm{KF}$ or $\mathrm{KNO}_{3}$, this new solid base exhibited a much higher basic strength $\left(\mathrm{H}_{-}=17.2\right)$ than the parent zeolite $\mathrm{NaY}$. However, the main disadvantages of this method are the complex operation and quite a long time needed, which limit the application in larger scale. Consequently a better way with a simpler process and a higher efficiency is found, and the microwave radiation method is chosen for the preparation of $\mathrm{Al}_{2} \mathrm{O}_{3}-\mathrm{NaY}$ porous materials due to the especial properties of microwave radiation stirring sample on molecular level.

$\mathrm{Al}_{2} \mathrm{O}_{3}$, with the particle size of 100 mesh, was ground first with zeolite $\mathrm{NaY}(\mathrm{Si} / \mathrm{Al}=2.68)$ at the weight ratio $\left(\mathrm{g}_{\mathrm{Al}_{2} \mathrm{O}_{1}} / \mathrm{g}_{\mathrm{NaY}}\right)$ of $0.1,0.3,0.5,0.7$ and 0.9 respectively, then irradiated in a microwave 